\title{
A Maximum Entropy Model Predicts the Potential Geographic Distribution of Sirex noctilio
}

\author{
Xueting Sun, Qiang Xu and Youqing Luo * \\ Sino-France Joint Laboratory for Invasive Forest Pests in Eurasia, Beijing Forestry University, Beijing 100083, \\ China; xuetingsun507@126.com (X.S.); xuqiangbj@foxmail.com (Q.X.) \\ * Correspondence: yqluo@bjfu.edu.cn
}

Received: 29 December 2019; Accepted: 3 February 2020; Published: 5 February 2020

\begin{abstract}
Sirex noctilio, the Sirex woodwasp, is an invasive pest that causes significant economic damage to native and commercial conifer stands through the introduction of a fungal wood decay pathogen. We combined the latitudes and longitudes of $S$. noctilio distribution points with historical climate data to predict its potential global distribution using a maximum entropy model implemented in the Maxent software. The annual mean temperature, the mean temperature of the warmest quarter, and the precipitation of the wettest month were important meteorological factors that affected the predictions, probably because they have a strong effect on the development of S. noctilio. Our predictions cover the most recent occurrence sites of $S$. noctilio in China. We predict that suitable habitats for S. noctilio are currently concentrated between $30^{\circ} \mathrm{N}$ to $60^{\circ} \mathrm{N}$ and $25^{\circ} \mathrm{S}$ to $55^{\circ} \mathrm{S}$ on the world map. All continents except for Antarctica contain suitable areas for S. noctilio, and such areas account for approximately $26 \%$ of the total area of these six continents. Predictions for 2050 and 2070 show that global climate change will affect the distribution of $S$. noctilio. With a decrease in carbon dioxide emissions, areas of moderate to high habitat suitability for S. noctilio will increase; with an increase in emissions, these areas will decrease.
\end{abstract}

Keywords: Sirex noctilio; invasive species; climate change; potential distribution

\section{Introduction}

The European woodwasp, Sirex noctilio Fabricius (Hymenoptera: Siricidae), is a wood-boring insect native to Eurasia and North Africa, which is known to attack dead and dying Pinus species in these regions, where the woodwasp is not generally considered to be a major pest of pine trees $[1,2]$. However, in the introduced countries, S. noctilio has caused severe damage to pine plantations and is considered a major pest of pine. According to the report, it was accidentally introduced to these countries, including New Zealand (first record 1900), Australia (1952), Uruguay (1980), Argentina (1985), Brazil (1988), South Africa (1994), Chile (2001), and United States (2004) [3-8]. Most introductions of $S$. noctilio was via trade routes [7]. In August 2013, S. noctilio was detected as a pest of Pinus sylvestris var. mongolica Litv in the Duerbote Mongolian Autonomous County, Daqing City, Heilongjiang Province, China ( $\left.\mathrm{N} 46^{\circ} 37^{\prime} 47^{\prime \prime}, \mathrm{E} 124^{\circ} 25^{\prime} 51^{\prime \prime}\right)$ [9]. According to the latest report, the damage of $S$. noctilio is found in Inner Mongolia Autonomous Region, Jilin and Liaoning Province in the northeast of China [10-12].

Due to its significance as a worldwide invasive pest, many studies have evaluated the potential global distribution of $S$. noctilio. Previous studies have used the climate-matching program CLIMEX, which is now widely employed to predict suitable habitats for insects [13]. The software uses the information on a species' biological characteristics and geographical distribution to predict the suitability of potential habitats in terms of climate. Based on climatic conditions in Eurasia and northern Africa where the insect is endemic, Carnegie (2006) predicted the potential distribution range of S. noctilio across the globe [14]. However, the study did not predict the occurrence of S. noctilio 
in Jilin, Liaoning, and Inner Mongolia, where it is now known to occur. Ireland (2018) also used process-oriented niche modeling in CLIMEX to predict the distribution of $S$. noctilio [15]. The seventeen distribution data points located in China fell predominantly into areas of moderate $(\approx 24 \%$, $)$ and high $(\approx 71 \%)$ S. noctilio suitability. However, according to the most recent study data, new distribution points of S. noctilio in Inner Mongolia and Liaoning Province are located in areas predicted to have marginal suitability. Therefore, based on the current distribution of S. noctilio in China, Ireland's predictions are conservative. This may reflect differences in the biological characteristics of S. noctilio from different regions or the omission of more recent occurrence data from China. Of course, the size of the prediction scale will also affect the prediction results. On a global scale, local areas may be overestimated or underestimated.

In contrast to CLIMEX, the maximum entropy model Maxent has been identified as the best predictive method when only species occurrence data are available. It has also been shown to perform well with limited training data [16-18]. Maxent is an open-source software package for modeling species niches and distributions through the application of a machine-learning technique called maximum entropy modeling. From a set of environmental (e.g., climatic) grids and geo-referenced occurrence locations, the model produces a probability distribution in which each grid cell has predicted suitability of conditions for the species. The maximum entropy model is a widely-used model for species distribution and has good prediction accuracy [17,19-21].

Here, we used the Maxent model and the newest S. noctilio occurrence data, particularly from China, to predict the potential occurrence of $S$. noctilio on a global scale. Our expectation is to improve the accuracy of global prediction results by supplementing China's data. We also predicted and compared current and future (2050 and 2070) S. noctilio distributions based on climate data and analyzed the meteorological factors that influence and limit its distribution. Understanding the potential global distribution and climate suitability patterns of pests such as $S$. noctilio is useful for forest managers and biosecurity officers when planning surveys, control strategies, and regulatory guidelines [22].

\section{Materials and Methods}

\subsection{Collection of Data on Distribution Points of S. noctilio in China and Other Countries}

S. noctilio distribution point data were collected from two sources. The data for S. noctilio in China were obtained from field surveys from 2013 to 2019. Surveys covered the northeast, northwest, and southwest of China. The main methods of field surveys include malaise traps (about 300) and dissecting of the damaged host logs (about 1000) [23]. The data for S. noctilio in other parts of the world were collected from literature references and websites. The two main websites were the Centre for Agriculture and Bioscience International (CABI, https://www.cabi.org/isc/) and the Global Biodiversity Information Facility (GBIF, https://www.gbif.org). To avoid repeated sampling within close distances, the Euclidean distance between any pair of distribution points was at least $10 \mathrm{~km}$. After screening, a total of 75 distribution points were retained for analysis, including 24 points from Northeast China. Fifty-one additional points were obtained from more than 15 countries, including Eurasian countries in S. noctilio's native range and countries such as Australia, South Africa, and the United States, where S. noctilio is invasive.

\subsection{Investigation on Main Autecology and Biology of S. noctilio in China}

While investigating the distribution points of $S$. noctilio, we conducted a series of studies on the reproduction and lifecycle of $S$. noctilio under the laboratory conditions [24]. The insect source was obtained by feeding in the logs collected from the forest. The flight capacity of $S$. noctilio was tested by Jiaduo flight mill system. 


\subsection{Climate Data}

Climate data were obtained from the WorldClim database (version 1.4, http://www.worldclim.org), a set of global climate layers (gridded climate data) with different spatial resolutions that can be used for mapping and spatial modeling. All data for current and future bioclimatic variables had a 5-min latitudinal and longitudinal spatial resolution, equivalent to approximately $9 \mathrm{~km}$ at the equator. Current climate data were generated by interpolation from 1960 to 1990.

The WorldClim database provides a total of 19 bioclimatic variables, denoted bio01-bio19, and we selected six for inclusion in the S. noctilio distribution model. Including an excessive number of variables rapidly increases the dimensions of ecological space and is not conducive to model predictions. In selecting variables for our model, we sought to avoid autocorrelation between variables and to retain those variables that could potentially limit the distribution of S. noctilio. We first excluded bio08 (mean temperature of the wettest quarter), bio09 (mean temperature of the driest quarter), bio18 (precipitation of warmest quarter), and bio19 (precipitation of coldest quarter). These four variables combine precipitation and temperature information into the same layer and exhibit spatial anomalies in the form of odd discontinuities between neighboring pixels $[25,26]$. Next, we performed a correlation analysis of the remaining 15 bioclimatic variables and used the absolute value of the Pearson correlation coefficient $(\leq 0.80)$ as a threshold for the exclusion of highly correlated variables (Figure 1). Six bioclimatic variables were retained: bio01 (annual mean temperature), bio07 (annual temperature range), bio10 (mean temperature of the warmest quarter), bio12 (annual precipitation), bio13 (precipitation of the wettest month), and bio15 (precipitation seasonality) (Table 1).

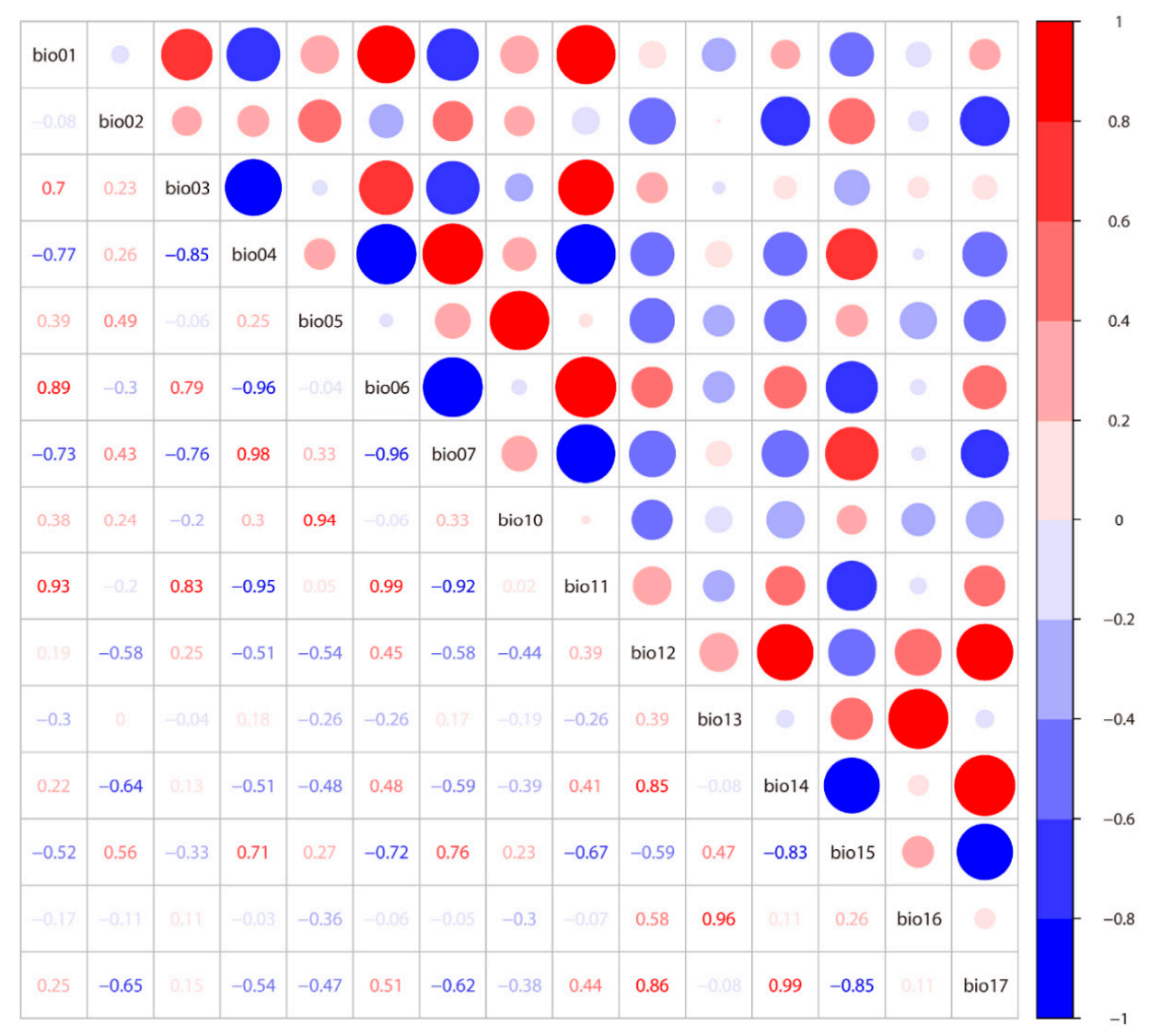

Figure 1. Correlation analysis of 15 bioclimatic variables. Red represents positive correlation, blue represents negative correlation, and the darker the color, the stronger the correlation. The size of the circle represents the strength of the correlation, and the larger the circle represents the stronger the correlation. These values are correlation coefficients. 
Table 1. Six bioclimatic variables from the WorldClim database that were retained after preliminary screening.

\begin{tabular}{cc}
\hline Abbreviation & Bioclimatic Variables \\
\hline Bio01 & Annual Mean Temperature \\
Bio07 & Temperature Annual Range (Bio05-Bio06) \\
Bio10 & Mean Temperature of Warmest Quarter \\
Bio12 & Annual Precipitation \\
Bio13 & Precipitation of Wettest Month \\
Bio15 & Precipitation Seasonality (Coefficient of Variation) \\
\hline
\end{tabular}

Future climate data were obtained from the Coupled Model Intercomparison Project Phase 5 global climate model under the Community Climate System Model 4 general model for three representative concentration pathways (RCPs) in 2050 (2041-2060 average) and 2070 (2061-2080 average). The three $\operatorname{RCPs}\left(2.6,4.5\right.$, and $\left.8.5 \mathrm{~W} \mathrm{~m}^{-2}\right)$ differ in their projections of radiative forcing for the year 2100 [27,28]. RCP2.6 is an optimistic scenario in which the carbon dioxide equivalent concentration reaches $450 \mathrm{ppm}$ in 2100 and the global average temperature increases by $0.2-1.8^{\circ} \mathrm{C}$. RCP4.5 is a moderate scenario in which the carbon dioxide equivalent concentration reaches $650 \mathrm{ppm}$ in 2100 and the global average temperature increases by $1.0-2.6{ }^{\circ} \mathrm{C}$. Finally, RCP8.5 is a pessimistic scenario in which the carbon dioxide equivalent concentration reaches $1350 \mathrm{ppm}$ in 2100 and the global average temperature increases by $2.6-4.8^{\circ} \mathrm{C}$.

\subsection{Setting Parameters in Maxent}

We used the open-source software package Maxent v.3.4.0, which can be downloaded from http://biodiversityinformatics.amnh.org/open_source/maxent/. The following parameters were used in the basic settings: random seed, a random test percentage of 25, 10 replicates, and a replicated run type of 'subsample'. By setting the random test percentage to $25 \%, 75 \%$ of the distribution points were randomly selected for the training set and the remaining $25 \%$ were used for the test set. By setting the number of replicates to 10, the model was run 10 times with the same settings, and the output of all runs was averaged to obtain the final result. In the advanced settings, we set the maximum number of iterations to 5000 and selected the 'write plot data' option. Maxent permits the specification of feature classes, i.e., transformations of the model covariates that enable the modeling of complex relationships [29]. The combination of specified feature classes depends on the number of distribution points, and based on the 75 distribution points in our study, we specified linear, quadratic, and hinge features.

Regularization provides a method to reduce model overfitting, and the predictive performance of the Maxent is influenced by the choice of regularization multiplier. We tested six values of the regularization multiplier $(0.5,1,1.5,2,2.5$, and 3$)$, and the area under the receiver operating characteristic curve (AUC) was highest with a regularization multiplier of 1 . The regularization multiplier was therefore set to 1 in the present study, and all remaining parameters were set to the software defaults.

\subsection{Classification of Suitable Areas for S. noctilio}

The classification of suitable areas for S. noctilio was performed using ArcGIS software v.10.2 (ESRI, Redlands, CA, USA). The ASCII output file from Maxent was transformed into a raster format using the Arc Toolbox tool in ArcGIS, and the layer was reclassified using Reclass in the Spatial Analyst tool. At present, the classification of suitable habitat areas is largely based on experience, and there is no unified standard. We used the natural groupings inherent in the Maxent output to delineate four suitability areas for S. noctilio using the Jenks classification in ArcGIS: high habitat suitability, moderate habitat suitability, low habitat suitability, and unsuitable habitat. 


\section{Results}

\subsection{Main Autecology and Biology of S. noctilio in China}

S. noctilio usually completes one generation per year in Heilongjiang Province. The only host of S. noctilio is P. sylvestris var. mongolica. The maximum cumulative flight distance of females is 56.25 $\mathrm{km}$, and that of males is $30.80 \mathrm{~km}$. One female lays 97.58 eggs throughout its life. The oviposition frequency of $S$. notilio is positively correlated with temperature from 17.49 to $23.15^{\circ} \mathrm{C}$.

\subsection{Model Evaluation}

The average omission and predicted area for $S$. noctilio were obtained after 10 rounds of modeling in Maxent (Figure 2A). As shown in the receiver operating characteristic (ROC) curve in Figure 2B, the AUC value of the model is greater than $0.9(0.946 \pm 0.014)$, indicating that the construction of this model has reached an excellent standard. In summary, this model can be used to predict suitable habitat areas for $S$. noctilio.
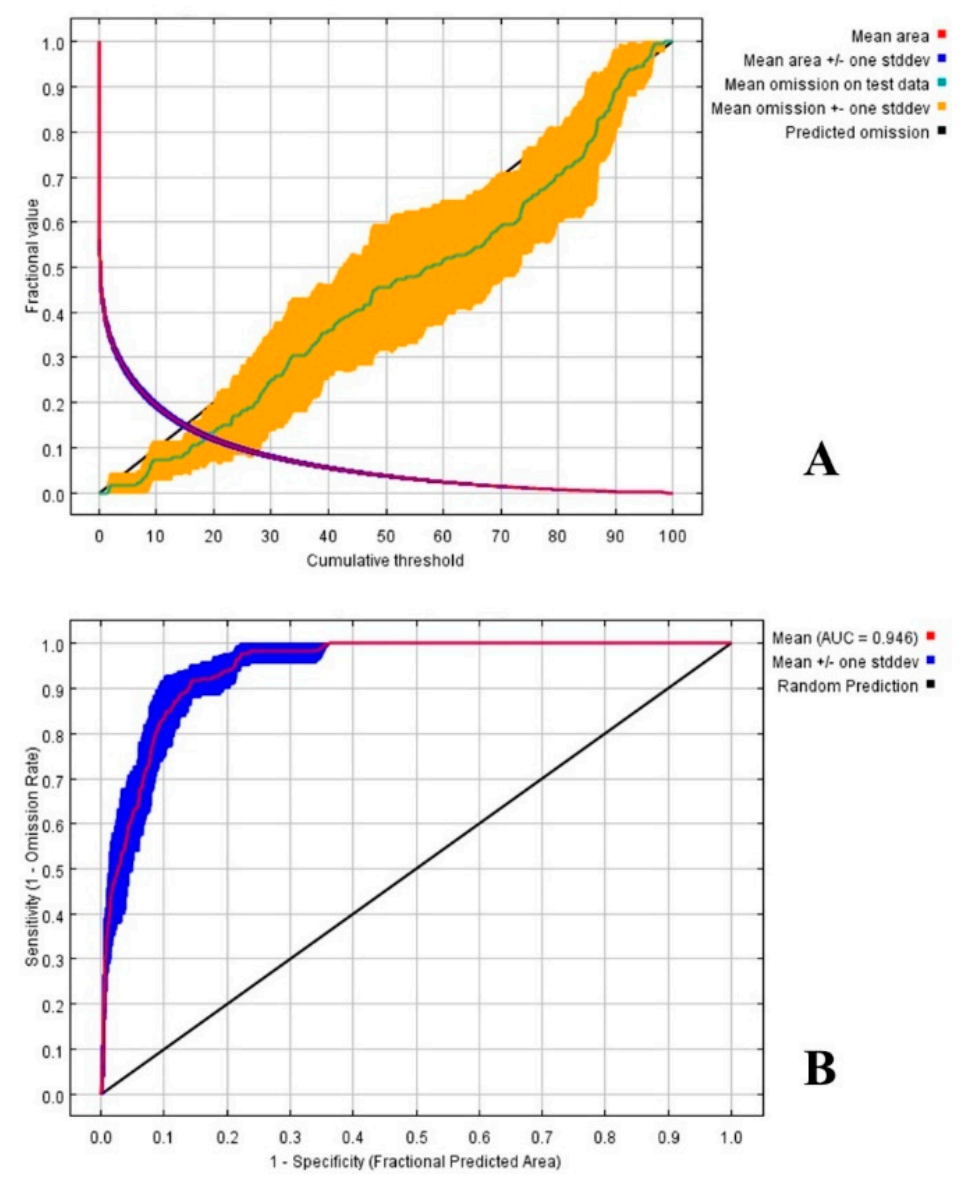

Figure 2. Model prediction accuracy analysis. (A) Average omission and predicted area for Sirex noctilio; (B) Average sensitivity vs. 1-specificity for Sirex noctilio.

\subsection{Relationships between S. noctilio Distribution and Bioclimatic Variables}

The importance of each bioclimatic variable to the distribution of S. noctilio is shown in a jackknife test plot (Figure 3A). All values are means of 10 replicate runs. For each variable, the greater the length of the blue bar, the greater the importance of that variable to the distribution of $S$. noctilio. By contrast, the shorter the green bar, the more information the variable has that other variables do not have. This type of unique information has an important influence on the distribution of S. noctilio. 
The three bioclimatic variables with the greatest influence on $S$. noctilio distribution are annual mean temperature (bio01), mean temperature of the warmest quarter (bio10), and precipitation of the wettest month (bio13). The response curves in Figure 3B-D show how changes in each variable affect the probability of $\mathrm{S}$. noctilio presence; each curve shows the mean of 10 replicate Maxent runs in red and the mean \pm one standard deviation of the replicate runs in blue. Each of the curves represents a different model, namely, a Maxent model created using only the corresponding variable. The plots reflect both the dependence of predicted habitat suitability on the selected variable and the dependencies induced by correlations between the selected variable and other variables.
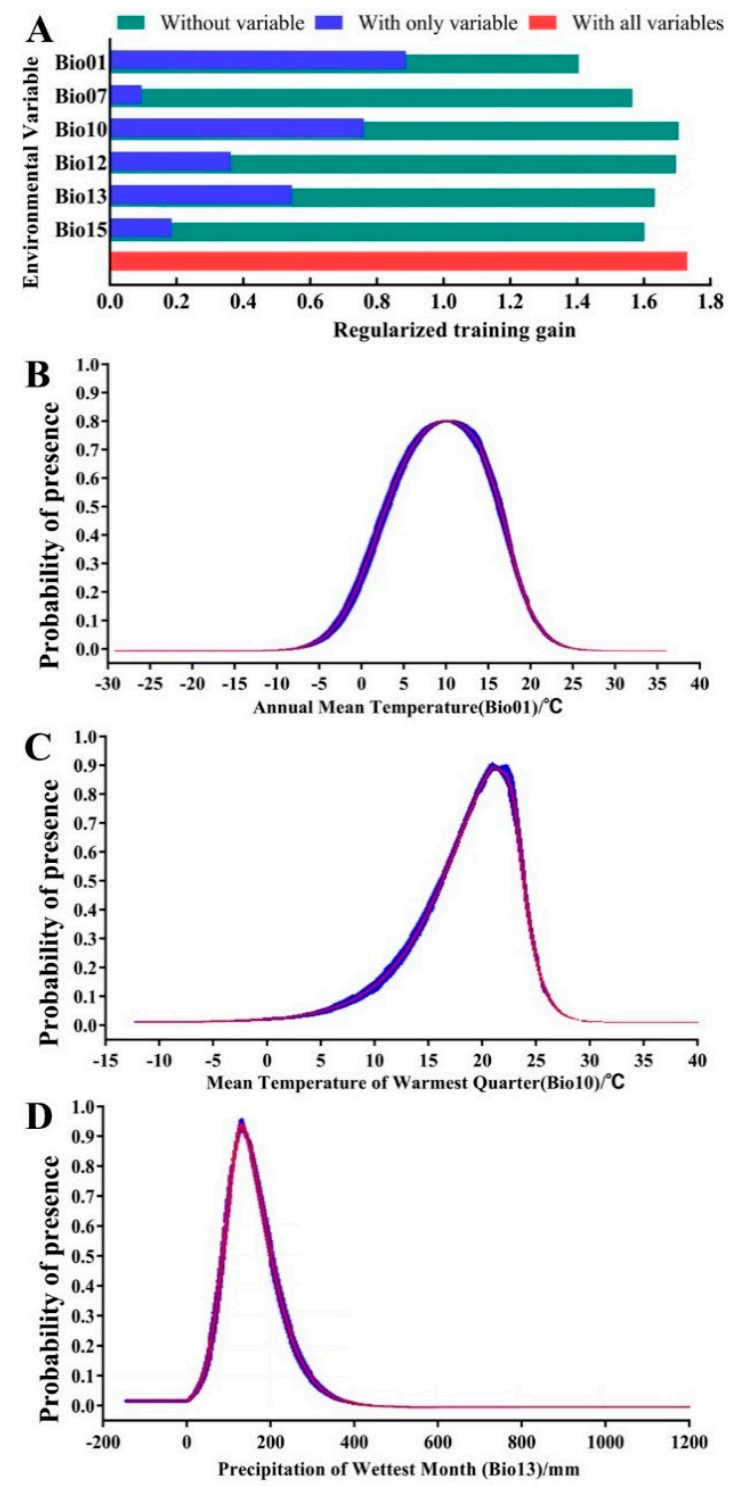

Figure 3. Jackknife test plot (A) and response curves of bioclimatic variables (B-D) that affect the distribution of S. noctilio. (A) "Without variable" represents the regularized training gain of the model without this variable, "With only variable" represents the regularized training gain of the model with only this variable, "With all variable" represents the regularized training gain of the model with all variable, (B) Response curve of annual mean temperature (bio01), (C) Response curve of mean temperature of the warmest quarter (bio10), (D) Response curve of precipitation of the wettest month (bio13).

The most suitable annual mean temperature for $S$. noctilio presence is $10^{\circ} \mathrm{C}$. The probability of S. noctilio presence increases with increasing the annual average temperature from -10 to $10{ }^{\circ} \mathrm{C}$, then 
decreases with increasing the annual mean temperature from 10 to $25^{\circ} \mathrm{C}$. In the warmest quarter, the most suitable mean temperature is $21^{\circ} \mathrm{C}$. The probability of $S$. noctilio presence increases as mean temperature in the warmest quarter increases from 0 to $21^{\circ} \mathrm{C}$, then decreases as mean temperature in the warmest quarter increases from 21 to $30^{\circ} \mathrm{C}$. In the wettest month, the optimum precipitation for $S$. noctilio presence is $140 \mathrm{~mm}$. The probability of $S$. noctilio presence increases as precipitation in the wettest month increases from 0 to $140 \mathrm{~mm}$, then decreases as precipitation increases from 140 to $460 \mathrm{~mm}$ in the wettest month.

\subsection{Currently Suitable Habitat Areas for S. noctilio Based on Historical Climatic Conditions}

A current habitat suitability map for $S$. noctilio based on maximum entropy model predictions is shown in Figure 4; it is based on the historical data of six bioclimatic variables and the current distribution data of $S$. noctilio. Regions suitable for $S$. noctilio are concentrated in the range of $30^{\circ} \mathrm{N}$ to $60^{\circ} \mathrm{N}$ and $25^{\circ} \mathrm{S}$ to $55^{\circ} \mathrm{S}$ on the world map. All continents except for Antarctica contain suitable areas for S. noctilio, and such areas account for approximately $26 \%$ of the total area of these six continents. Regions of high habitat suitability are found mainly in New Zealand, Australia, South Africa, Brazil, the United States, China, France, and the United Kingdom. The new S. noctilio occurrence sites that we have recently investigated in China are all located within high habitat suitability regions. The map also indicates that $S$. noctilio is more likely to be present near the ocean in countries within its predicted range.

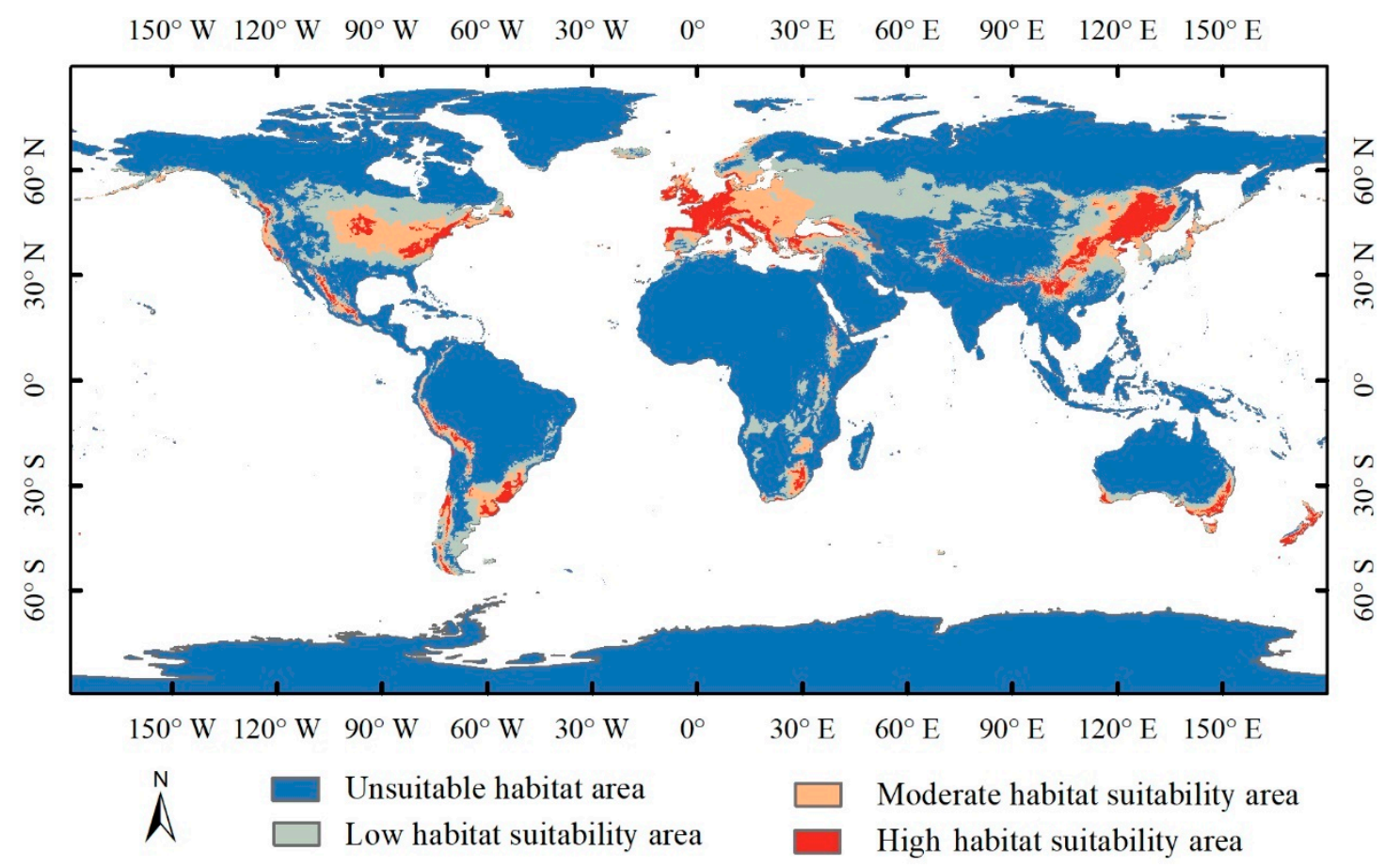

Figure 4. The predicted range of currently suitable areas for S. noctilio under historical climatic conditions.

\subsection{Potential Distribution of S. noctilio under Future Climate Scenarios}

In future models of $S$. noctilio distribution, the AUC values under three RCP scenarios (RCP2.6, $\mathrm{RCP} 4.5$, and RCP8.5) were $0.915 \pm 0.014,0.938 \pm 0.023,0.943 \pm 0.017$, respectively, in 2050 and $0.937 \pm 0.015,0.940 \pm 0.010,0.947 \pm 0.012$, respectively, in 2070 , all of which were greater than the 0.9 AUC threshold.

Habitat suitability maps for these models are shown in Figure 5, and the percentage areas of different habitat suitability types under various climate scenarios is shown in Table 2. The change in 
percent area of different habitat suitability types can be determined by calculation. In 2050 and 2070 , if carbon dioxide emissions are high and RCP is large, the suitable area for $S$. noctilio will be reduced. However, if emissions and RCP are low, the suitable area will be enlarged. Although the direction of change is the same, the degree of change is different for different habitat types. For example, as carbon dioxide emissions increase, the high suitability area for S. noctilio decreases nearly twice as much as the moderate suitability area. The current distribution is broadly similar to that predicted under the RCP4.5 scenario in 2050 and 2070.

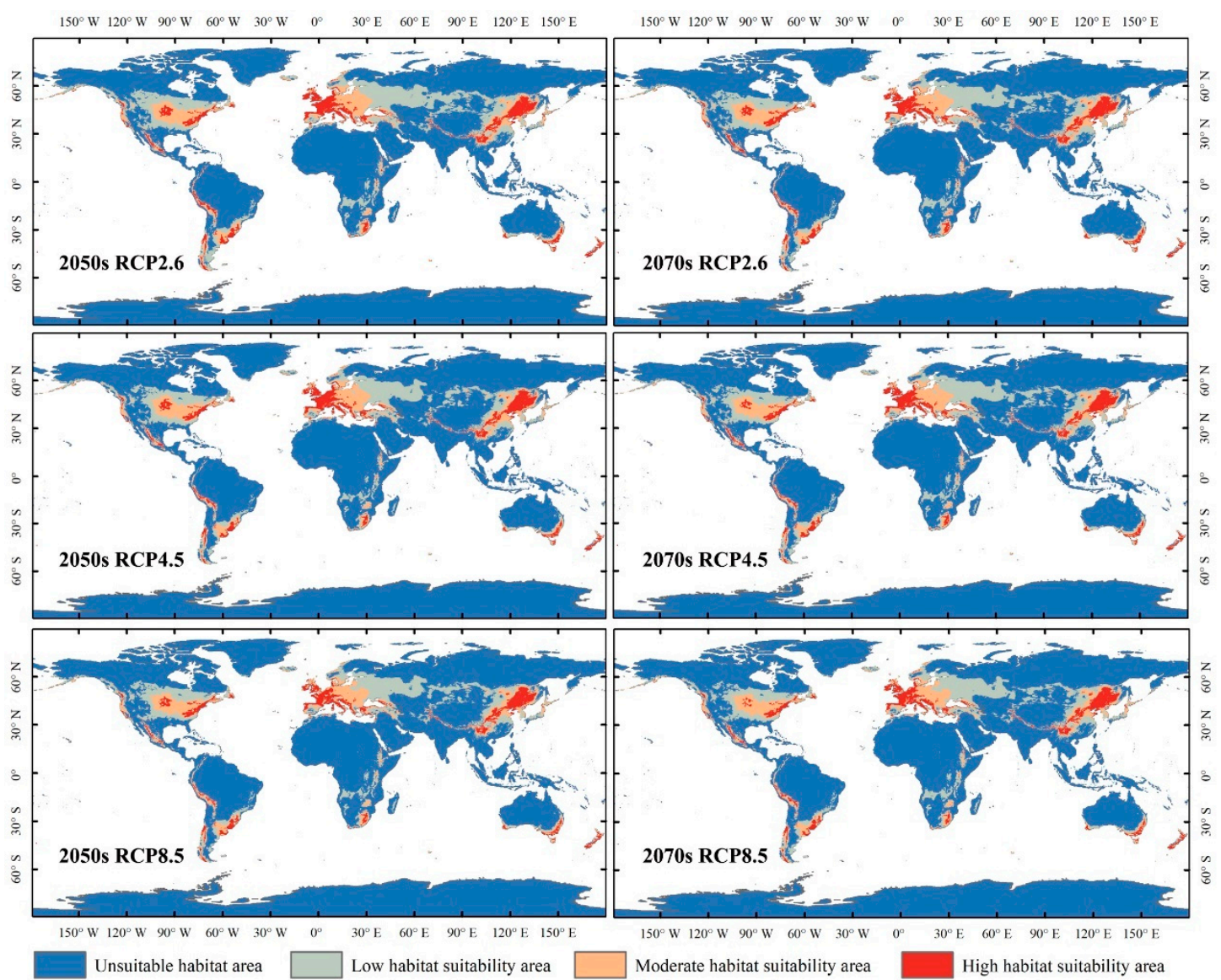

Figure 5. Prediction of the future range of suitable areas for S. noctilio under various representative concentration pathway (RCP) scenarios in 2050 and 2070.

Table 2. Percentage land surface area of different $S$. noctilio habitat suitability types under various climate scenarios.

\begin{tabular}{ccccc}
\hline \multirow{2}{*}{ Date and RCP } & \multicolumn{4}{c}{ Percentage of Different Areas (\%) } \\
\cline { 2 - 5 } & $\begin{array}{c}\text { Unsuitable } \\
\text { Habitat Area }\end{array}$ & $\begin{array}{c}\text { Low Habitat } \\
\text { Suitability Area }\end{array}$ & $\begin{array}{c}\text { Moderate Habitat } \\
\text { Suitability Area }\end{array}$ & $\begin{array}{c}\text { High Habitat } \\
\text { Suitability Area }\end{array}$ \\
\hline Current & 73.63 & 15.01 & 7.04 & 4.32 \\
2050 RCP2.6 & $72.12(-1.51)$ & $15.79(+0.78)$ & $7.27(+0.23)$ & $4.82(+0.50)$ \\
2050 RCP4.5 & $75.11(+1.48)$ & $13.46(-1.55)$ & $7.05(+0.01)$ & $4.39(+0.07)$ \\
2050 RCP8.5 & $74.92(+1.29)$ & $14.11(-0.90)$ & $6.90(-0.14)$ & $4.07(-0.25)$ \\
2070 RCP2.6 & $73.68(+0.05)$ & $14.54(-0.47)$ & $7.18(+0.14)$ & $4.60(+0.28)$ \\
2070 RCP4.5 & $74.66(+1.03)$ & $14.01(-1.00)$ & $7.02(-0.02)$ & $4.30(-0.02)$ \\
2070 RCP8.5 & $75.03(+1.40)$ & $13.91(-1.10)$ & $6.88(-0.16)$ & $4.17(-0.15)$ \\
\hline
\end{tabular}

Note: Values in parentheses that show the change from the Current percentage area. 


\section{Discussion}

A comprehensive study of current methods for species distribution modeling found that the maximum entropy model outperformed nearly all other methods [16]. Nonetheless, the Maxent software does have several limitations. First, the AUC values of the fitted model can be used to assess whether it is reasonable but cannot confirm that it is accurate. "Various goodness-of-fit procedures available" is a solution available through re-expression as a Poisson point process model [30]. However, specific methods require further study. Second, there is no evaluation standard for setting software parameters such as the regularization multiplier. Merow (2013) recommends exploring a range of regularization coefficient values and choosing a value that maximizes some measure of fit on a cross-validation data set [31]. In our study, we explored a series of coefficient values, but our limited exploration may not have found the optimal multiplier.

Climatic variables are known to have a direct effect on insect population dynamics through the modulation of survival, developmental rate, fecundity, and dispersal [32,33]. Damage significance and spatial distribution of $S$. noctilio infestations in New Zealand were compared with the growth and suitability outputs of a model to explore whether the impact of $S$. noctilio was related to climate. However, no correlation between modeled climate suitability and field infestation severity was found [15]. In our study, a few key bioclimatic variables had an important effect on distribution prediction. Annual mean temperature (bio01) was the main environmental variable associated with $S$. noctilio distribution at the global level. Of course, in addition to climate factors, the distribution of S. noctilio was also limited by other factors such as latitude, which is a surrogate for day length and critical photoperiod and plays an indirect role through climate.

The mean omission of the test data and the predicted omission were very similar. According to the definition of the cumulative threshold, this shows that the effect of model construction is very good [34,35]. However, in this study, the assessment of the suitability for S. noctilio is based only on the Maxent tool that uses climate data. In fact, the development and spreading of an insect species is crucially dependent on the breeding base, i.e., distribution of the host tree [36]. In the introduced area of S. noctilio, there is a phenomenon worth paying attention to. S. noctilio are very harmful to non-native pine species [7]. In the Southern Hemisphere, S. noctilio has attacked and killed several species of introduced North American pines, including jack pine (Pinus banksiana Lamb.), Caribbean pine (Pinus caribaea Morelet), lodgepole pine (Pinus contorta Dougl.), shortleaf pine (Pinus echinata Mill.), slash pine (Pinus elliottii Engelm.), Jeffrey pine (Pinus jeffreyi Grev. and Balf.), longleaf pine (Pinus palustris Mill.), Mexican weeping pine (P. patula Schiede and Schltdl. and Cham.), ponderosa pine (P. ponderosa Laws.), Monterey pine (Pinus radiata D. Don.), Chiapas white pine (Pinus chiapensis (Martİnez) Andresen), and loblolly pine (Pinus taeda L.) [7]. Many of these species come from the origin location of S. noctilio. In China, the only host of S. noctilio, P. sylvestris var. mongolica, is a variety of the origin host in Europe. The planting of the original hosts in the world are conducive to the invasion of the European woodwasp [7,37]. When the planting range of hosts are reduced, the suitable area of $S$. noctilio will also decrease. That is how climate indirectly affects $S$. noctilio through their hosts.

Climate change affects forest insect pest populations in a number of ways. It is predicted to have demonstrable effects on the frequency and intensity of pest outbreaks, particularly at the margins of host ranges [38,39]. Interestingly, our 2050 and 2070 predictions suggest that a favorable inflection point for the control of $S$. noctilio is coming. In the future, emissions of carbon dioxide and other greenhouse gases will probably increase from the present level. In that circumstance, the distribution of $S$. noctilio predicted under RCP8.5 conditions is more likely to become a reality. Under the RCP8.5 scenario, the range of suitable areas for S. noctilio will narrow, benefiting efforts to control S. noctillo and preventing its spread. The increase of greenhouse gas carbon dioxide emissions will increase the temperature, directly affect the climate, and indirectly affect the survival of insects and other organisms through the climate $[40,41]$. In its native areas, $S$. noctilio is a common organism; however, in introduced areas causing damage, S. noctilio is an invasive pest. Even though S. noctilio is a pest it still is an organism that has its value. If $S$. noctilio is regarded only as an invasive pest, then an increase in atmospheric 
carbon dioxide concentration will reduce its range of harm. However, if the woodwasp is regarded as a common organism, a reduction in its range of suitable habitats is not good news. As greenhouse gas emissions increase, the habitat range of many other organisms, including humans, may also decrease. The pressure on coniferous species might still increase dramatically due to higher abundances. It is also very likely that climate change will increase the number of severe pest outbreaks in the near future [42]. In order to increase the long-term effect of prevention, biodiversity of monospecific forests highly disposed to $S$. noctilio invasion and spreading should be improved. It is suggested that different species of trees should be mixed.

The life cycle of $S$. noctilio is normally completed in one year, but may require two years in colder parts of its range [7]. Larvae must meet a certain accumulated temperature to emerge as an adult. This is why annual mean temperature (bio01) is one of the climatic factors that influence the distribution of S. noctilio. That is how climate affects $S$. noctilio directly [43].

\section{Conclusions}

In this study, Maxent software was used to predict the distribution of $S$. noctilio based on climate variables. Using the maximum entropy model, the latest distribution data obtained a better distribution range. The annual mean temperature, the mean temperature of the warmest quarter, and the precipitation of the wettest month were important meteorological factors that affected the predictions. Climate variables indirectly affect the distribution of $S$. noctilio through the host, or directly affect its distribution through the development of $S$. noctilioc. Different from previous studies, this study found that the overall distribution of $S$. noctilioc tends to be smaller under the trend of global warming, rather than larger.

Author Contributions: Conceptualization, X.S. Q.X. and Y.L.; methodology, X.S. and Q.X.; software, X.S. and Q.X.; validation, Y.L.; formal analysis, X.S. and Q.X.; investigation, X.S. and Q.X.; data curation, X.S. and Q.X.; writing—original draft preparation, X.S.; writing-review and editing, X.S. and Q.X.; visualization, X.S. and Q.X.; supervision, Y.L.; project administration, Y.L.; funding acquisition, Y.L. All authors have read and agreed to the published version of the manuscript.

Funding: This research was funded by Beijing's Science and Technology Planning Project, grant number Z191100008519004.

Acknowledgments: We thank workers of the forestry departments in Heilongjiang, Liaoning, Jilin provinces, and Inner Mongolia Autonomous Region for their assistance with fieldwork. This study was supported based on the Memorandum of Understanding between The China Scholarship Council and Agreenium (a French public establishment for scientific cooperation bringing together the main agricultural and veterinary research organizations and higher education establishments in France).

Conflicts of Interest: The authors declare no conflict of interest.

\section{References}

1. Spradbery, J.P.; Kirk, A.A. Aspects of the ecology of siricid woodwasps (Hymenoptera: Siricidae) in Europe, North Africa and Turkey with special reference to the biological control of Sirex noctilio F. in Australia. Bull. Èntomol. Res. 1978, 68, 341-359. [CrossRef]

2. Haugen, D.A. Sirex woodwasp: Biology, ecology and management. In Proceedings of the 17th US Department of Agriculture Interagency Research Forum on Gypsy Moth and Other Invasive Species 2006; Gen. Tech. Rep. NRS-P-10; US Department of Agriculture, Forest Service, Northern Research Station: Newtown Square, PA, USA, 2006; pp. 48-49.

3. Rawlings, G. Recent observations on the Sirex noctilio population in Pinus radiata forest in New Zealand. N. Z. J. For. Sci. 1948, 5, 411-421.

4. Iede, E.T.; Penteado, S.; Bisol, J. Primeiro registro de ataque de Sirex noctilio em Pinus taeda no Brasil; Embrapa/Centro Nacional de Pesquisas Florestais: Curitiba, Brazil, 1988.

5. Madden, J.L. Sirex in Australasia. In Dynamics of Forest Insect Populations; Plenum Publisher: New York, NY, USA, 1988; pp. 407-429. 
6. Tribe, G. The woodwasp Sirex noctilio Fabricius (Hymenoptera: Siricidae), a pest of Pinus species, now established in South Africa. Afr. Entomol. 1995, 3, 215-217.

7. Hoebeke, E.R.; Haugen, D.A.; Haack, R.A. Sirex noctilio: Discovery of a Discovery of a Palearctic Siricid Woodwasp in New York. Newsl. Mich. Entomo. Soc. 2005, 50, 24-25.

8. Slippers, B.; Hurley, B.P.; Wingfield, M.J. SirexWoodwasp: A Model for Evolving Management Paradigms of Invasive Forest Pests. Annu. Rev. Èntomol. 2015, 60, 601-619. [CrossRef]

9. Li, D.; Shi, J.; Lu, M.; Ren, L.; Zhen, C.; Luo, Y. Detection and Identification of the Invasive Sirex noctilio (Hymenoptera: Siricidae) Fungal Symbiont, Amylostereum areolatum (Russulales: Amylostereacea), in China and the Stimulating Effect of Insect Venom on Laccase Production by A. areolatum YQL03. J. Econ. Èntomol. 2015, 108, 1136-1147. [CrossRef]

10. Sun, X.; Tao, J.; Ren, L.; Shi, J.; Luo, Y. Identification of Sirex noctilio (Hymenoptera: Siricidae) Using a Species-Specific Cytochrome C Oxidase Subunit I PCR Assay. J. Econ. Èntomol. 2016, 109, 1424-1430. [CrossRef]

11. Wang, L.; Liu, X.; Ren, L.; Shi, J.; Luo, Y. Variety of endophytic fungi associated with conifers in mixed conifer forests invaded by Sirex noctilio. Sci. Silvae Sin. 2017, 53, 81-89. [CrossRef]

12. Chengcheng, L.; Lixiang, W.; Lili, R.; Huadong, L.; Youqing, L. Effects of Temperature Adaptation of Symbiotic Wood-decay Fungus Amylostereum areolatum on Potential Distribution Area of Sirex noctilio. J. Northeast For. Univ. 2019, 47, 112-117. [CrossRef]

13. Kriticos, D.J.; Maywald, G.F.; Yonow, T.; Zurcher, E.J.; Herrmann, N.I.; Sutherst, R. Exploring the effects of climate on plants, animals and diseases. CLIMEX Version 2015, 4, 184.

14. Carnegie, A.J.; Matsuki, M.; Haugen, D.A.; Hurley, B.P.; Ahumada, R.; Klasmer, P.; Sun, J.; Iede, E.T. Predicting the potential distribution of Sirex noctilio (Hymenoptera: Siricidae), a significant exotic pest of Pinus plantations. Ann. For. Sci. 2006, 63, 119-128. [CrossRef]

15. Ireland, K.B.; Bulman, L.; Hoskins, A.J.; Pinkard, E.A.; Mohammed, C.; Kriticos, D.J. Estimating the potential geographical range of Sirex noctilio: Comparison with an existing model and relationship with field severity. Boil. Invasions 2018, 20, 2599-2622. [CrossRef]

16. Elith, J.; Graham, C.H.; Anderson, R.P.; Dudík, M.; Ferrier, S.; Guisan, A.; Hijmans, R.J.; Huettmann, F.; Leathwick, J.R.; Lehmann, A.; et al. Novel methods improve prediction of species' distributions from occurrence data. Ecography 2006, 29, 129-151. [CrossRef]

17. Phillips, S.J.; Anderson, R.P.; Schapire, R.E. Maximum entropy modeling of species geographic distributions. Ecol. Model. 2006, 190, 231-259. [CrossRef]

18. Zhu, G.; Liu, Q.; Gao, Y. Improving ecological niche model transferability to predict the potential distribution of invasive exotic species. Biodivers. Sci. 2014, 22, 223-230. [CrossRef]

19. Phillips, S.J.; Dudík, M.; Schapire, R.E. A maximum entropy approach to species distribution modeling. In Proceedings of the Twenty-First International Conference on Machine Learning-ICML'04, Banff, AB, Canada, 4-8 July 2004; p. 83.

20. Phillips, S.J.; Dudík, M. Modeling of species distributions with Maxent: New extensions and a comprehensive evaluation. Ecography 2008, 31, 161-175. [CrossRef]

21. Phillips, S.J.; Anderson, R.P.; Dudík, M.; Schapire, R.E.; Blair, M.E. Opening the black box: An open-source release of Maxent. Ecography 2017, 40, 887-893. [CrossRef]

22. Venette, R.C. Climate Analyses to Assess Risks from Invasive Forest Insects: Simple Matching to Advanced Models. Curr. For. Rep. 2017, 3, 255-268. [CrossRef]

23. Xu, Q.; Cao, L.; Ma, J.; Ren, L.; Sun, X.; Luo, Y.; Shi, J. Study on the morphology and damage characteristics of Sirex noctilio. J. Environ. Entomol. 2018, 40, 299-305. [CrossRef]

24. Xu, Q.; Lv, H.; Wu, C.; Mao, Y.; Song, G.; Shi, J. Oviposition behavior of Sirex noctilio (Hymenoptera: Siricidae). Acta Entomol. Sin. 2019, 62, 468-474. [CrossRef]

25. Escobar, L.E.; Lira-Noriega, A.; Medina-Vogel, G.; Peterson, A.T. Potential for spread of the white-nose fungus (Pseudogymnoascus destructans) in the Americas: Use of Maxent and NicheA to assure strict model transference. Geospat. Health 2014, 9, 221. [CrossRef]

26. Zhu, G.-P.; Peterson, A.T. Do consensus models outperform individual models? Transferability evaluations of diverse modeling approaches for an invasive moth. Boil. Invasions 2017, 19, 2519-2532. [CrossRef] 
27. Van Vuuren, D.P.; Edmonds, J.; Kainuma, M.; Riahi, K.; Thomson, A.; Hibbard, K.; Hurtt, G.C.; Kram, T.; Krey, V.; Lamarque, J.-F.; et al. The representative concentration pathways: An overview. Clim. Chang. 2011, 109, 5-31. [CrossRef]

28. Rogelj, J.; Meinshausen, M.; Knutti, R. Global warming under old and new scenarios using IPCC climate sensitivity range estimates. Nat. Clim. Chang. 2012, 2, 248-253. [CrossRef]

29. Morales, N.S.; Fernández, I.C.; Baca-González, V. MaxEnt's parameter configuration and small samples: Are we paying attention to recommendations? A systematic review. PeerJ 2017, 5, e3093. [CrossRef]

30. Renner, I.W.; Warton, D.I. Equivalence of MAXENT and Poisson Point Process Models for Species Distribution Modeling in Ecology. Biomtrics 2013, 69, 274-281. [CrossRef]

31. Merow, C.; Smith, M.J.; Silander, J.A. A practical guide to MaxEnt for modeling species' distributions: What it does, and why inputs and settings matter. Ecography 2013, 36, 1058-1069.

32. Messenger, P.S. Bioclimatic Studies with Insects. Annu. Rev. Èntomol. 1959, 4, 183-206. [CrossRef]

33. Andrewartha, H.G.; Birch, L.C. The Ecological Web: More on the Distribution and Abundance of Animals; University of Chicago Press: Chicago, CA, USA, 1986.

34. Swets, J. Measuring the accuracy of diagnostic systems. Science 1988, 240, 1285-1293. [CrossRef]

35. Peterson, A.T.; Soberón, J.; Pearson, R.G.; Anderson, R.P.; Martínez-Meyer, E.; Nakamura, M.; Araújo, M.B. Ecological Niches and Geographic Distributions (MPB-49); Princeton University Press: Princeton, NJ, USA, 2011; Volume 56.

36. Régnière, J.; St-Amant, R.; Duval, P. Predicting insect distributions under climate change from physiological responses: Spruce budworm as an example. Biol. Invasions 2012, 14, 1571-1586. [CrossRef]

37. Mattson, W.J.; Niemelä, P. Invasion of North American Forests by European Phytophagous Insects. Bioscience 1996, 46, 741-753. [CrossRef]

38. Pureswaran, D.S.; Roques, A.; Battisti, A. Forest Insects and Climate Change. Curr. For. Rep. 2018, 4, 35-50. [CrossRef]

39. Volney, W.A.; Fleming, R.A. Climate change and impacts of boreal forest insects. Agric. Ecosyst. Environ. 2000, 82, 283-294. [CrossRef]

40. Danks, H. Arctic Insects as Indicators of Environmental Change. Arctic 1992, 45, 159-166. [CrossRef]

41. Williamsen, L.; Pigeon, G.; Mysterud, A.; Stien, A.; Forchhammer, M.; Loe, L.E. Keeping cool in the warming Arctic: Thermoregulatory behaviour by Svalbard reindeer (Rangifer tarandus platyrhynchus). Can. J. Zool. 2019, 97, 1177-1185. [CrossRef]

42. Hu, G.; Xie, M.-C.; Lin, Z.-X.; Xin, D.-Y.; Huang, C.-Y.; Chen, W.; Zhang, X.-X.; Zhai, B.-P. Are Outbreaks of Nilaparvata lugens (Stål) Associated with Global Warming? Environ. Èntomol. 2010, 39, 1705-1714. [CrossRef]

43. Ramesh, K.; Niranjana, G.; Kelageri, S.S. Chapter-5 Diversity and Survival of Insects in Arctic Environment. In Advances; AkiNik Publications: New Delhi, India, 2019; pp. 83-100. 